Association for Information Systems

AIS Electronic Library (AISeL)

\title{
Towards Sustainable Transport: A Strategic Decision Support System for Urban Logistics Operations
}

\author{
Maximilian Heumann \\ Leibnitz Universität Hannover \\ Richard Pump \\ Hochschule Hannover \\ Michael H. Breitner \\ Leibnitz Universität Hannover \\ Arne Koschel \\ Hochschule Hannover \\ Volker Ahlers \\ Hochschule Hannover
}

Follow this and additional works at: https://aisel.aisnet.org/wi2021

Heumann, Maximilian; Pump, Richard; Breitner, Michael H.; Koschel, Arne; and Ahlers, Volker, "Towards Sustainable Transport: A Strategic Decision Support System for Urban Logistics Operations" (2021). Wirtschaftsinformatik 2021 Proceedings. 2.

https://aisel.aisnet.org/wi2021/SSmartCity/Track08/2

This material is brought to you by the Wirtschaftsinformatik at AIS Electronic Library (AISeL). It has been accepted for inclusion in Wirtschaftsinformatik 2021 Proceedings by an authorized administrator of AIS Electronic Library (AISeL). For more information, please contact elibrary@aisnet.org. 


\title{
Towards Sustainable Transport: A Strategic Decision Support System for Urban Logistics Operations
}

\author{
Maximilian Heumann ${ }^{1}$, Richard Pump², Michael H. Breitner ${ }^{1}$, Arne Koschel² and \\ Volker Ahlers ${ }^{2}$ \\ ${ }^{1}$ Leibniz University Hannover, Information Systems and Management Institute, Hannover \\ \{heumann,breitner\}@iwi.uni-hannover.de \\ ${ }^{2}$ University of Applied Sciences and Arts Hannover, Dept. of Computer Science, Hannover \\ \{richard.pump, arne.koschel, volker.ahlers\}@hs-hannover.de
}

\begin{abstract}
Global urbanization for decades has led to unprecedented levels and growing demands for urban logistics. Thus, problems such as congestion, environmental noise, and urban sprawl are growing. As a result, many cities face problems of optimal decision-making regarding green and sustainable smart transportation systems and infrastructures. However, various possible measures and logistics concepts are available to improve urban logistics, while effects are unclear and difficult to predict. To meet the growing need for future-oriented decisions by city authorities, we developed a decision support system prototype that allows a strategic simulation-based evaluation of different logistics concepts regarding defined targets, e.g., pollutant emissions, traffic flow, space requirements, or economic efficiency on a city district level. An expert system for the strategic evaluation of logistics concepts on a city district level is integrated to achieve transferability and scalability.
\end{abstract}

Keywords: Urban Logistics, Liveable City, Data-Driven Government, Decision Support System, Expert System

\section{Introduction}

The world's urban population is growing rapidly and already accounts for $55 \%$ of the total population, a share that the UN expects to rise to $68 \%$ by 2050 [1]. Together with the continuous growth of e-commerce, urbanization is leading to a rising transport demand in cities. The ongoing digital transformation and emerging digital business models in urban food, beverage, and parcel delivery are causing an increasingly dynamic transport demand characterized by time-critical services. The recent global COVID-19 pandemic has further changed the logistics industry's landscape and strongly intensified this already growing parcel delivery demand [2-3]. As a result, many cities face growing challenges to their transport systems and infrastructure that affect the urban population's health and quality of life, such as congestion, environmental noise, CO2 emissions, accidents, and urban sprawl. The future transport system, the cityscape, and the cities' quality of life will depend on city authorities' actions regarding the urban transport landscape.

16th International Conference on Wirtschaftsinformatik,

March 2021, Essen, Germany 
One way city authorities can influence the future transport and mobility system of a city is to promote innovative logistics concepts. Since the most cost-intensive part of the supply chain in parcel delivery is urban "last mile" delivery [4], logistics providers also have an interest in urban transport and try to optimize their business through various innovative concepts. The call for sustainable and future-oriented decisions by city authorities is therefore pushed by various possible measures and logistics concept developments of service providers to improve urban transport. It is then necessary for decision-makers to ex-ante assess on a strategic level which of the available logistics concepts are likely to achieve the best effects depending on the requirements. Since the impact of a logistics concept depends not only on the concept itself but also on the distinctive attributes of a city or district, this is a complex issue of uncertain effects, which must be considered in each specific case. The impacts of a logistics concept may vary in districts with different populations or built environments.

Furthermore, testing logistics concepts within a city district by implementing smallscale pilot projects is neither cost-efficient nor useful. The uncertainty concerning suitable logistics concepts for a more sustainable future is growing. Especially with the rising number of delivery companies, the need for decision support regarding the strategic planning of logistics initiatives in urban areas is increasing from an Information Systems (IS) perspective [5], [6]. The described challenges lead us to our research question:

How can an IS support decision-makers in the strategic planning of urban logistic concepts while assessing its economic and environmental impacts?

We investigate this question following a Design Science Research (DSR) approach and develop a technological artifact that integrates three components into a holistic decision support system (DSS): prototype: (1) a simulation-based micro- and macro-scale database for scenarios of urban logistics concepts; (2) an integral expert system (ES) to provide scalability and transferability enabling individual problem specifications; and (3) a user-oriented web application to assess the impact of logistics concepts on traffic, economic as well as environmental objectives and to map the decision making of economic actors.

The focus of this article is on the technical design of these components and their integration. We instantiate the artifact as a DSS prototype and apply it in a case study based on real-world data to enable a proof of concept. Also, expert assessments are included in the evaluation [7], [8].

First, related scientific work is described in section 2. Afterward, section 3 presents the applied research design. Subsequently, the DSS prototype development with database development, integral ES and the web-based platform is introduced in section 4. Section 5 demonstrates the applicability of the DSS prototype and serves to evaluate our artifact. After elaborating limitations and future research perspectives in section 6 , we complete our article with a conclusion in section 7 . 


\section{$2 \quad$ Related Work}

Relevant related work includes research on urban logistics, DSS, and ES for urban logistics. The majority of literature in the area deals with optimizing existing technologies and traditional urban freight operations. Lagorio et al. identify focus areas in urban logistics to suggest the best possible directions for future research [6]. They conclude that municipal administrations' decision support receives growing attention in current research as reasonable decisions in urban development are increasingly relevant and urgent [6], [9]. However, research in this area is still underrepresented and ex-ante approaches need to be addressed more intensively.

In a more recent review, Dolati et al. further emphasize the importance of decision support for city authorities in the context of urban logistics and point out the relevance of stakeholder involvement [10]. The initiative "Urban Transport Roadmaps" funded by the European Commission, developed a web-based DSS for urban transport. The project group implemented an informative platform for city authorities to evaluate future mobility scenarios in urban areas in a time horizon up to 2030, allowing the comparison of different urban structures and a selection of measures for urban transport. The quantified effects of various measures (e.g. car sharing, prioritized public transport) are based on modeling future macroeconomic trends. The project parties do not consider any micro-scale traffic effects of logistics concepts in city districts. The portfolio of measures is limited to regulatory actions and mobility services. Their web-tool thereby aims at a different use-case, showing detailed traffic development predictions for entire cities instead of predicted impacts of novel logistics concepts on traffic on a city district scale [11].

With a decision support framework for simulation-based ex-ante assessment of regulatory measures for urban logistics, Bozzo et al. suggest a more disaggregated approach. However, the authors remain with a theoretical framework without an actual application. The approach does not specify any logistics concepts and is moderately scalable; in any case, very resource-intensive simulations are necessary for an assessment. The developed model did not lead to an application [12].

Sarra et al. also highlight a lack of applicable simulation-based DSS approaches in a literature review. The sensitivity of existing models on urban commercial vehicle flows is limited when evaluating individually tailored measures in urban districts [1315], [5]. These models focus on individual vehicle movements and neglect logistic and traveler behavior underlying these movements [5], [16].

While DSS are well established in urban logistics, ES are less common. ES are computer-based IS, designed to represent expert domain knowledge to provide solutions to problems that generally require a large scope of expert knowledge [8], [17]. Against this background, despite complex information and knowledge in urban logistics, we only identified one article that directly addresses an ES in the field of urban logistics. Schröder et al. [16] conceive a conceptual framework for an ES to analyze smart policies for urban courier-express-parcel (CEP) transport but remain with a conceptual framework, without application. Besides, urban logistics also combines other sectors, such as food deliveries, shopping and service trips, or trips by tradespeople and medical care services, and as such is much more complex than stand-alone CEP transport. 
In summary, although the relevant literature provides substantial preliminary studies, there is a lack of practical solutions for user-oriented strategic decision support for city authorities in planning sustainable urban logistics at the micro-scale level, despite growing relevance. In both, literature streams and the expert opinions of conducted interviews, decision support implementation based on spatially disaggregated information is considered promising. However, designing an applicable DSS is challenging, requiring further research on practical solutions [5-6], [10-12].

\section{$3 \quad$ Research Approach}

We tackle this research gap from an IS perspective by creating a technological artifact following the DSR approach of Peffers et al. [18]. The introduction to our research is considered problem-centered according to the DSR approach. Our research motivation results from a real-world problem as part of a collaborative project, namely the support of strategic decisions for system integration of logistics concepts to improve urban transport.

To define our problem-solving objectives, we analyzed the scientific literature on research streams on urban logistics. We conducted expert interviews and workshops with urban transport planners, from which we derive our core requirements. We use modeling elements for the optimal design of logistics concept scenarios from the literature on decision support for sustainable logistics concepts. These modeled scenarios serve as the basis for the conducted simulations. Knowledge about relevant decision target values resulted from the expert interviews and periodical workshops. From the literature on the development of application-oriented ES and DSS, we used the knowledge of system design elements to create a scalable and transferable architecture that is easy to implement. With our technological artifact, we investigate a possible approach for strategic decision support for district-specific logistics while remaining flexible concerning different innovative logistics concepts.

To demonstrate the use of the designed artifact, we instantiated the technical backand front-end of a DSS prototype. We conducted a case study based on real-world data in Hannover, Germany. To evaluate our DSS prototype, we compared our case study results with the effects expected by experts in Hannover. Involved practitioners and experts work in the automotive industry, the CEP delivery sector, logistics, transport, and urban planning. The experts based their conclusions on their experience and the evaluation of the simulations carried out. We evaluated the congruence of the results with the experts' expectations and considered different cases. Two cases concern districts for which the concepts were simulated, i.e., data are available in the database. In two other cases, we analyzed a district similar to the representative pilot districts and a district that differs significantly from our representative districts' structural parameters, for which no data are available and the ES is triggered. 


\section{DSS Prototype for Urban Logistics}

The pursued DSR approach provides improvements for both the rigor and the relevance of DSS research. However, DSS artifacts are often criticized for their lack of relevance to practice and for neglecting configurability and contextual dynamics [19-20]. To counteract this lack, we oriented our DSS prototype development towards essential DSS design elements [21]. We worked towards the highest possible practical relevance, configurability and contextual dynamics [19]. Practitioners and experts from the fields of transport planning and logistics were involved throughout the development process to achieve a high relevance to practice. The architecture of the DSS prototype with its main components is illustrated in Figure 1. By applying our DSS prototype, users are presented with general impact tendencies of defined concepts on eight key performance indicators (KPIs): pollutant emissions, traffic flow, space requirements, economic efficiency, costs, innovative substance, technology acceptance and ecological efficiency, which have been identified in expert interviews and workshops as most significant and relevant for city authorities.

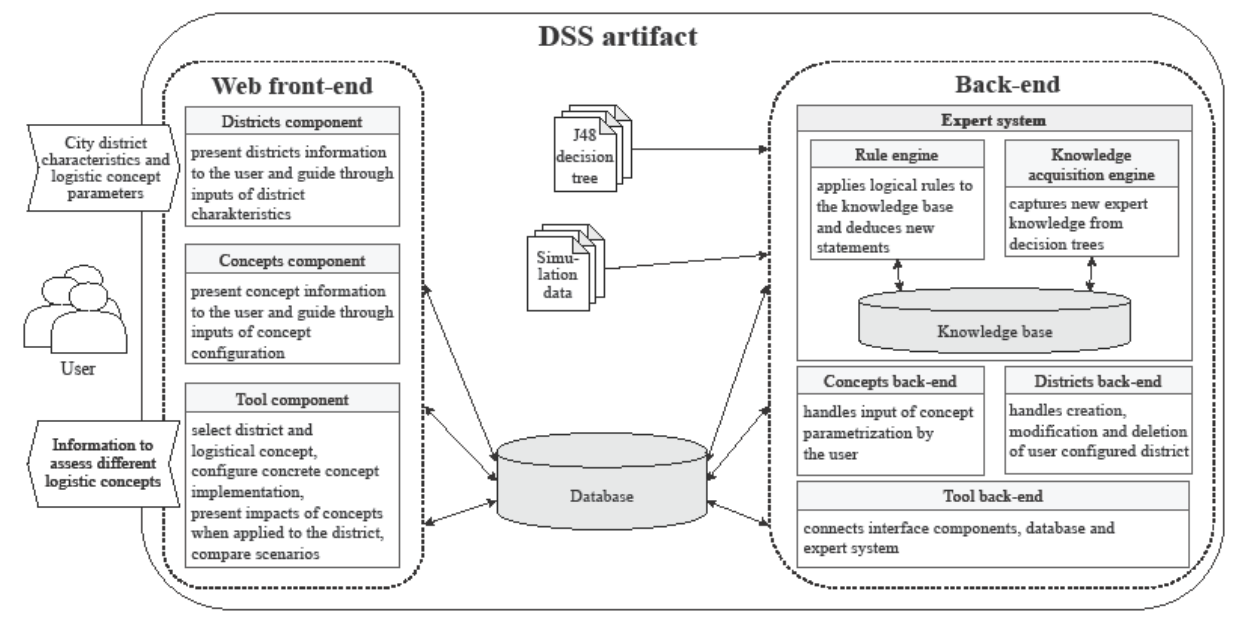

Figure 1. DSS architecture.

To evaluate the logistics concepts' effects, users choose from a selection of representative district types and preset logistics concepts, or individually configure both the district parameters and the desired concepts. The districts' inputs are mainly structural parameters and statistical features such as population density, the share of individual population groups, registered cars, living space per inhabitant. Concept parameters include specific characteristics such as hub capacities, degree of supply fleet electrification, percentage of the participating population. By using the tool component, concepts can then be compared and examined for their effects and impacts.

If the desired scenario corresponds to a simulated scenario, the simulation database provides the information for the evaluation. If individual scenarios are to be examined, the ES and knowledge database in the backend is used to check the fact inputs and infer 
effects. To provide an efficient and easily scalable solution, we implemented an upload function that allows extending the knowledge base with human-readable decision trees, which are then automatically processed and implemented in the rules engine. Moreover, the database can be extended by uploading new simulation results.

In the following sections, the development process regarding (1) the database, (2) the development of the integral ES, and (3) the development of the user interface of our web-based DSS, with all functionalities for input, output, and presentation of decisionrelated data, is explained.

\subsection{Creating the Database}

The first step in creating the DSS was creating a database containing the KPI impacts of logistics concepts on the representative district types. To create the database, three steps were executed within the collaborative project USEfUL: (1) the identification of projects and concepts for sustainable urban logistics, (2) the definition of simulated logistics concepts and scenarios and (3) the acqusisition of domain knowledge through expert assisted simulations. The process was supported by experts from the automotive sector, parcel delivery services, and urban transport planning. Fig. 2 shows the process from data collection to results analysis.

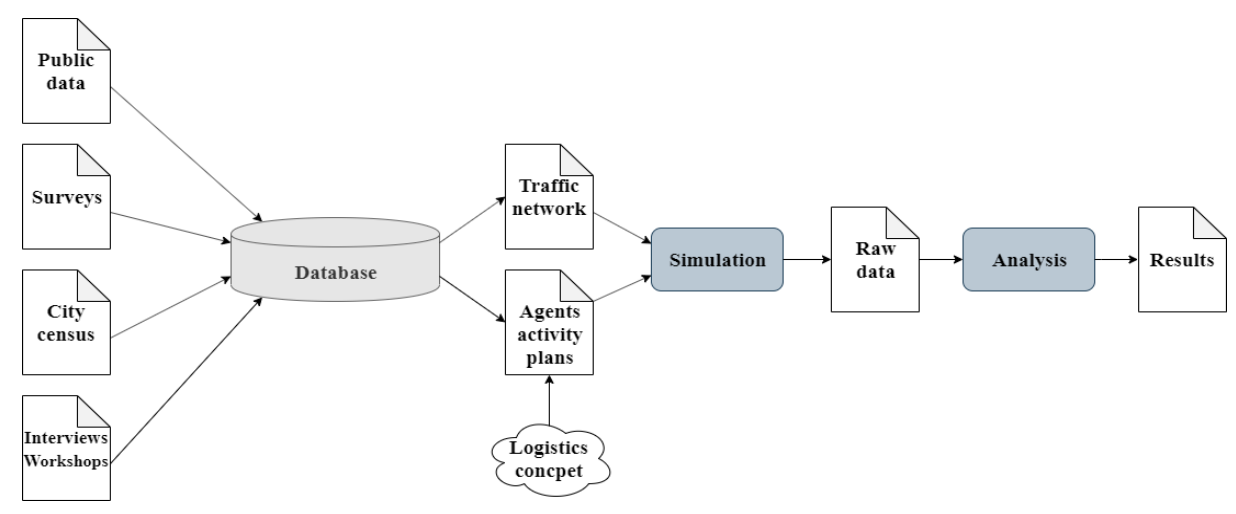

Figure 2. Process of logistics concept and scenario simulations

First, necessary data regarding urban logistics and citizen behavior were collected from different sources like public data repositories, surveys, expert interviews and workshops. Sources include OpenStreetMap, General Transit Feed Specification (GTFS) data [22], the latest German mobility study "Mobilität in Deutschland" (MiD) [23], and the survey of German Mobility Panel (MOP) [24]. Independent surveys and interviews supplement the data. All data were collected in a database to generate a model of the current traffic in Hannover's city. The spatially disaggregated database is crucial for decision support on the level of city districts. The detailed process of model creation and simulation process can be found in [25] and [26]. Starting from a basic scenario, which represents the current transport and mobility landscape in Hannover, different 
logistics scenarios like e-grocery, parcel pickup stations, Smart City Loop and others were modelled and simulated. For the logistics concepts' individual scenarios, literature reviews, surveys, and statistics were conducted, evaluated, and integrated into the models. The macro- and micro-scale simulations are carried out using MATSim framework and AnyLogic software. The raw output data produced by the simulations consist of large event files (essentially a record file of the simulation) and extensive statistics that need to be analyzed before results can be presented. Using data mining tools for event file analysis and models for cost and emission calculation, the impacts of the logistics concepts on the city districts were evaluated to produce a foundation upon which the DSS could be built.

\subsection{Integral Expert System}

The presented ES corresponds to a rule-based system and thus primarily consists of a knowledge base (consisting of rules) and the inference engine, to process corresponding knowledge and interpret fact inputs. Following Waterman's established guidelines, the development process of our ES includes the steps of identification, conceptualization, formalization, implementation, and testing [27]. As it is flexible, robust, and offers a practical approach for data analytics, we further adapted and applied the cross-industry standard process for data mining (CRISP-DM) methodology for our data and rules mining purposes [28]. Figure 3 presents the schematic development process in line with our DSR approach.

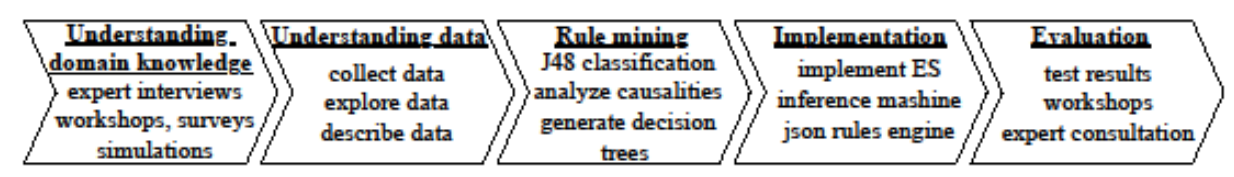

Figure 3. Process of ES development.

To develop the ES, an understanding of the domain knowledge in urban logistics, traffic, and city planning was initially established. We elaborated the problem, possible solutions, target values, and other decision factors in cooperation with experts. Moreover, we carried out a requirements analysis for the ES. All findings then lead to the simulations described in chapter 4.1. The simulation results provide the data basis for all further steps.

To process the results more efficiently and better understand the outputs, all numerical continuous output values were classified into ordinal data. The data were processed using the WEKA data mining tool and the $J 48$ classification algorithm to derive decision trees. The human-readable decision trees can then be transferred to the knowledge base through an automated interface. The interface translates the decision trees into rules for the inference engine. For the implementation of the integral ES as part of the DSS, appropriate interfaces were implemented within the backend to check user input and for the inference of results.

The algorithm used for rule mining, $J 48$, is an open-source Java implementation of the C4.5 statistical classification algorithm [29]. The algorithm is widely used and is 
considered best practice in data mining [30-32]. It offers a very efficient implementation and results that are easy to understand by the end user. A comprehensible human readable and interpretable rule base is necessary to achieve a hybrid intelligence of experts and computer systems.

The results of the rule mining classification are decision trees for each concept and effect. Each decision tree reflects the input parameters for which causal relationships were identified in the rule mining process. These facts can be both district-specific characteristics and concept parameters. The rules are used to derive positive, negative, or constant effects on local exhaust emissions for the specific concept.

After the rule base was created, the ES was implemented using the JavaScript-based json-rules-engine. The rules consist of simple JSON structures, making them humanreadable and easy to persist.

The functionality of the ES is illustrated in the architecture in Figure 1. Core components of the ES are the knowledge base consisting of the $J 48$ decision trees based on simulation results and expert knowledge, the rule engine for inferring results from input facts, and the facility to extend the knowledge base by uploading new decision trees. The ES implementation enables the user to create his or her configurations of districts and concept scenarios. The users' fact input is checked based on the rule base and causal effects are inferred and presented in a comprehensible way, similar to the output shown in Figure 4.

\subsection{The web-based DSS prototype}

The proper presentation of the collected evaluations and inferred data is paramount to their usefulness in city planning's daily activities. This requires a clear view of the system's purpose as well as primary users and use cases. Furthermore, the product quality of the web-based DSS needs to be closely monitored. To create an artifact of high user satisfaction, the design process needs to work extensively with future product users. Therefore, the first step of developing the DSS is identifying key users, and analyzing the use cases, describing system interactions. Main user groups of the DSS are city planners and urban decision-makers, like local politicians. During requirement analysis, we again used interviews and workshops to identify the main user groups' needs. With an ever-increasing amount of different logistics concepts and uncertain effects, keeping an overview becomes more challenging. City planners and politicians need a solution providing at-a-glance decision support.

During our interviews, we identified five major use cases for the DSS: (1) Collect information about logistics concepts, (2) collect information about predefined representative city districts, (3) configure an own individual district, (4) evaluate effects of logistics concepts in a district, (5) export evaluation results.

The main goal of the DSS needs to be the presentation of information, as users want to collect information and analyze connections between concrete implementations of logistics concepts and properties of city districts. The DSS needs to explain the processes involved in logistics concepts and parameters that define concrete implementations on a level that is quickly understood, preferably by using simple pictures. Similar to logistics concepts, the predefined representative city districts need to be presented 
with all characteristics relevant to city planning. Again, a graphical representation is preferred. Furthermore, users want to input own scenarios of own city districts if the representative districts do not cover preferences. While the representative districts aim to be representative of many other urban areas, not all possible districts can be covered with simulation data within the project's timeframe. Since therefore no data are available for user-configured districts, the application needs to infer information using the ES described in chapter 4.2. The essential function of the DSS is the presentation of the effects of logistics concepts within a given city district, e.g. the emission effects of using micro hubs for parcel delivery in urban area [33].

To expand user groups to the general public, enabling participation of citizens, the decision was made to provide the DSS as a web-based tool, instead of a standard desktop application or a smartphone app. In this way, not only political and administrative decision-makers are involved in logistics initiatives of the city, but also residents can use the platform to inform themselves about new logistics concepts. This allows us to provide an easy-to-use solution that does not require installation and can be used from many different devices.

Lastly, an export of the information is implemented to allow users to take the results, integrate them into presentations, and use them without access to the application. Since functional requirements are covered through the definition of use cases, quality requirements and technical restrictions need to be examined. A major quality requirement is a high degree of usability as defined by ISO25010 [34]. The projected user groups of city planners and decision makers are not technical specialists and do not necessarily have the time or motivation to learn the usage of a complex software system.

The technical restrictions were rather loose, as the city of Hannover already uses a wide range of web-servers and databases in their current operation. Therefore, modern technologies can easily be used without putting unnecessary strain on the IT-department.

Building on the defined vision of the DSS, the technical components can be designed. For most of the functionality, a simple database combined with an attractive front end suffices. Only the creation of own districts and the inference of new information requires more sophisticated elements of the ES. Figure 1 shows the rough architecture of the web-based DSS. Within the web-interface, three central components are implemented. The Districts and Concepts components will present the districts and concepts to users by accessing the information stored in the Database. In combination with its backend components, they further handle the creation, modification, and deletion of user configured districts and concept scenarios. The component Tool presents the main functionality, which uses the other two interface components, the Database, and the Rule Engine. Through the interface provided by the web-tool users can select a district and a logistics concept, configure the concrete concept implementation and is presented the impact of the concept when applied to the district. While all known combinations are loaded from the database, unknown combinations (i.e., selecting a user created district) query the rule engine for the rule-based inference of results.

Figure 4 shows a screenshot of the finished prototype. Since the DSS addresses German users from the public, political, and administrative milieu, the website is designed in German. The user first selects a city district and a logistics concept. After configuring 
the concrete implementation of the logistics concept, the user is presented the general tendencies on KPIs like emissions and costs. This process requires few interactions for a rough overview and presents results in an easily understandable way, achieving our initial design goals. Furthermore, a more in-depth inspection of concepts can be achieved by changing the concept parameters and creating own districts, which is not shown in the presented screenshot. The prototype also provides functionalities to inform about the innovative logistics concepts, the representative city districts and to compare different concepts in terms of their impact.

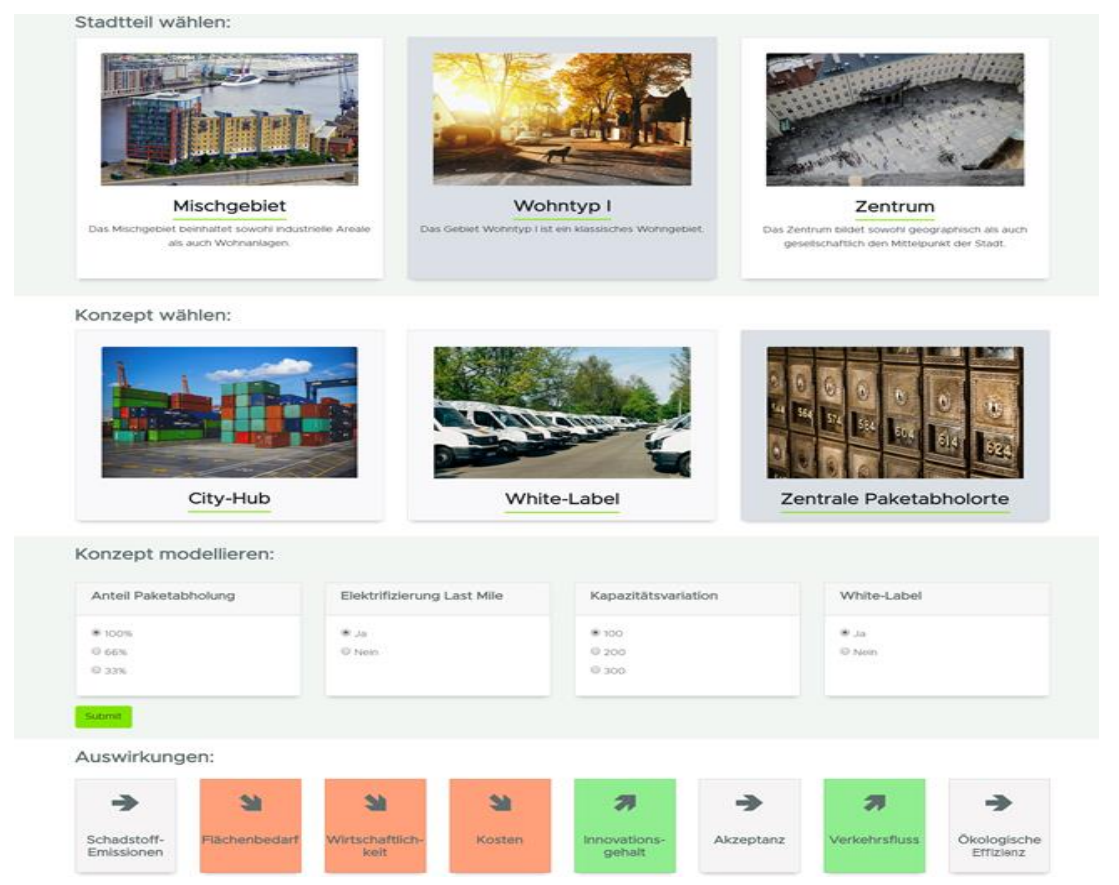

Figure 4. Screenshot from the web-based DSS prototype.

\section{$5 \quad$ Case Study and Discussion}

To demonstrate the applicability and evaluation of our DSS prototype as part of our DSR approach, we conducted a case study. We choose a use case in which the evaluation of a micro hub concept is performed in different environments. On the one hand, the performed simulations substantiate the validity of our DSS prototype, on the other hand all results were reviewed and evaluated by domain experts throughout the case study in focus group discussions.

For the applicability check, two Hannover districts were considered [35], which were simulated as two of the predefined representative districts. In terms of transferability, one structurally similar, and one strongly different district were also considered. The 
similar case is the district Dresden Neustadt [36] that is similar to the Hannover district Oststadt. The structurally different area is the district Hohenstein in Wolfsburg [37]. For the case study it was necessary to enter structural data of the four study areas. This includes values such as population (absolute and relative as a proportion of total cities population), area (absolute and relative as a proportion of total city area), population density, number of private households and commercial establishments, average population per household, number of registered cars and commercial vehicles, number of social security employees, unemployment rate, and more. In addition, the concepts to be investigated can be assessed by input on the degree of delivery penetration in the district, the capacity of the micro hubs in packages, the selection of optimized or nonoptimized locations, or the white-label (WL) or conventional delivery. As requested by the experts, results are presented in roughly classified trends (see Figure 5).

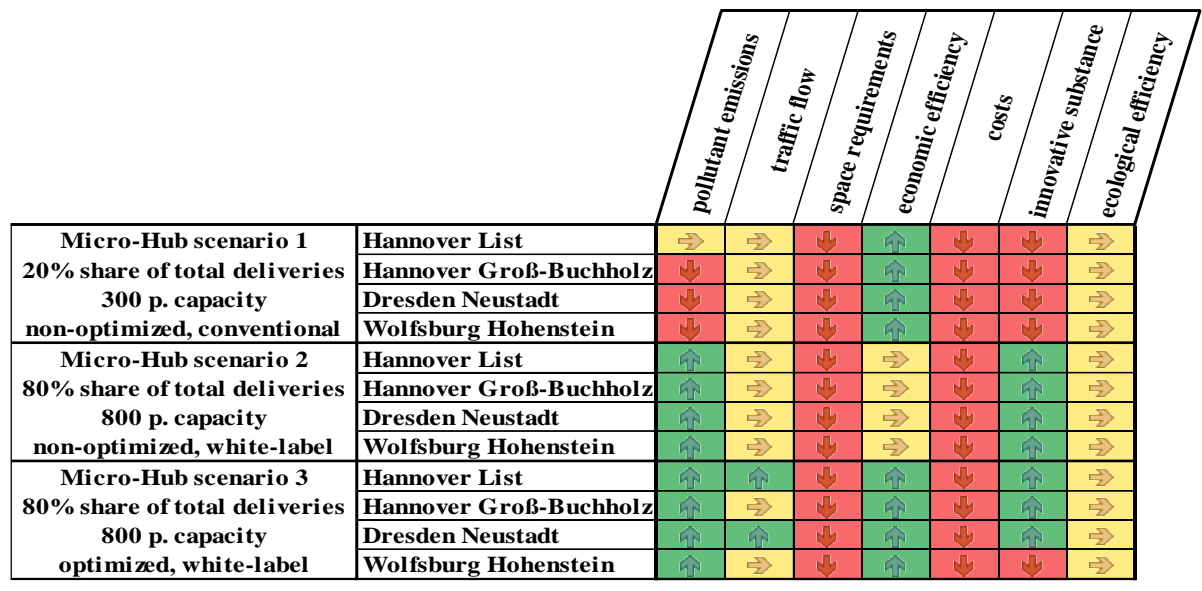

Figure 5. Case study results for different concept scenarios and city districts.

It is apparent that the DSS prototype for each scenario can show a trend for all of the defined KPIs in an ordinal scale of three levels. Involved domain experts were able to judge all of the outputs as valid. Despite the very different scenarios, the district structures have little effect on the impact. The three different concepts are more likely to have the most significant impact. The results also show that a standalone WL delivery does not necessarily positively affect traffic flow. Rather, in addition to the WL delivery, an optimized infrastructure of hub locations is required to utilize all operating CEP transport providers' capacities optimally. The KPIs of costs and space requirements seem to be increasing regardless of any variation. However, given the cost-intensive micro-hub concept with high capital commitment, the consulted experts believe this is a realistic effect [33]. The experts also point out that for the third concept scenario, it is striking that the positive changes in traffic flow depending on the similarity of districts testify to the DSS prototype's validity. The similar districts Dresden Neustadt and Hannover List show a positive effect, whereas the more suburban-like districts Wolfsburg Hohenstein and Hannover Groß-Buchholz show no positive effect. According to the experts, the case study allows to confirm that the application meets the requirements 
set. Our DSS prototype allows realistic statements about logistics concepts in known and unknown districts through the presented tendencies. This confirms the basic transferability of the application. However, it must also be pointed out that the inferred statements about unknown districts cannot be validated by a simulation basis because they are only given on the foundation of derived causalities by the ES.

Consequently, effects in transferred city districts are plausible but not validated. According to experts in urban planning, the results are sufficiently explicit for strategic decision support and at the same time, adequately fuzzy to be suitable for public use. According to the requirement, the results are understandable for political decision-makers and city dwellers without expert knowledge.

However, it is noted that the results in the implemented classification rather address all stakeholders on a political level for first assessments of different logistics concepts. Regarding our requirement for a scalable DSS, our upload function offers a way for expanding the database with new districts and logistics concepts, thus providing an efficient and easy-to-use solution. In the course of conducting the case study, we received further positive feedback on the user-friendliness of the system with regard to the objectives of our artifact. Transparent user workflows and easy navigation throughout the entire websites received particular emphasis. The suggestions for improvement of the DSS prototype included the expansion of the database and the integration of further structural traffic parameters primarily.

\section{$6 \quad$ Limitations and Future Research}

This study has several limitations that must be addressed. In the presented case study, only seven of the eight identified KPIs can be depicted yet. For the eighth value of technology acceptance, we are currently surveying to add results after completion. As the system is self-contained, the knowledge base can easily be expanded with the new knowledge from the completed study.

Beyond that, all of the presented results base on simulations and expert knowledge referring to our four selected representative pilot districts in Hannover. As the case study and focus group discussions indicated, further simulations are necessary to expand the database and the knowledge base for a seamless validation of logistics scenarios even in unknown districts or city types and structures. Experts also state that other key figures on individual districts' transport infrastructure can be decisive and show certain relations with the effects of logistics concepts.

However, no infrastructural peculiarities such as rotary traffic or road types were in our work due to the selection of the four representative pilot districts. Another limitation concerning the representative pilot districts in Hannover became apparent since all districts are similar in their structure. Therefore, the inclusion of traffic infrastructure metrics and a more diverse and broader selection of city districts for simulations and data acquisition are recommended, specifically with regard to the rule mining process.

Although our results are based on simulations resulting in continuous numeric output values, only three scaled tendencies should be shown to the end-user to be understandable to a wide range of different knowledge backgrounds. Showing general tendencies 
only, the application can be opened to the public, presenting information not only to strategic city planners but also to interested citizens possibly affected by decisions made using the DSS. Since the effects of individual concepts in specific urban districts can be perceived as threatening and can worry affected citizens, continuous numerical values were not desired, and the ordinal scale was required to be limited to three categories. In doing so, we contribute to our objective of the involvement of stakeholders. This requirement leads to the limitation of a rather vague three-level output of the DSS. To provide a more detailed assessment for application experts, user authorization and administration could be included in the system to provide separate expert functions.

Regarding the latest COVID-19 pandemic, another limitation arises, as we did not consider the changing mobility and transport behavior and other effects of such a pandemic and the resulting correlations related to logistics concepts [2]. Given the ongoing situation and a growing risk of similar pandemics and catastrophes in the future, such effects should be investigated and included in further research. Future research can also focus on accompanying the implementation of pilot projects of logistics concepts in cities with the presented DSS's help. For this purpose, field studies could be carried out together with experts and the effects predicted by the DSS could be compared with real data from logistical pilot projects.

\section{Conclusions}

In this paper, we presented our developed DSS providing IS-based strategic decision support for urban logistics. For a well-founded development process based on existing literature on DSS in urban logistics and related disciplines, we used a DSR approach. The developed DSS artifact shows significant progress compared to existing approaches [5-6], [9-10]. The DSS provides transferable and scalable strategic decision support for political and administrative decision-makers and involves other stakeholders, such as the public. The insights result from the expert knowledge of practitioners in the fields of traffic models and simulations as well as from scientific literature. A case study and focus group discussion served to test the practicability of the model.

The DSS is a useful and enriching tool for the strategic planning of urban logistics concept initiatives, and funding, towards a liveable city. It serves as decision support and information platform for political and administrative authorities and the public, who can evaluate existing transport structures for the effects of innovative logistics concepts to assess and classify the feasibility of such concepts and resulting benefits. The DSS draws on a comprehensive simulation and knowledge database and uses an integral ES to derive unknown city district structures' effects. Expert interviews have shown that these elements have a great potential to support strategic decision making, especially on a level of political processes.

The simulation and knowledge database should be extended to further urban structures and metrics, and data should be condensed in future work. The provided ordinal scale of results should also be extended from three to five or seven levels based on the condensed data for more precise assessments beyond the strategic dimension. 
Acknowledgement. This work is funded by the German Federal Ministry of Education and Research project "USEfUL" (grant ID 03SF0547). The authors cordially thank all USEfUL partners, too.

\section{References}

1. United Nations Department of Economic and Social Affairs (UN-DESA): World Urbanization Prospects: The 2018 Revision (2018)

2. Choi, T.M.: Innovative "bring-service-near-your-home" operations under Corona-virus (COVID-19/SARS-CoV-2) outbreak: Can logistics become the messiah?. Transportation Research Part E: Logistics and Transportation Review, vol. 140, p.101961 (2020)

3. Singh, S., Kumar, R., Panchal, R., Tiwari, M.K.: Impact of COVID-19 on logistics systems and disruptions in food supply chain. International Journal of Production Research, pp. 1-16 (2020)

4. Gevaers, R., Van de Voorde, E., Vanelslander, T.: Characteristics of innovations in last-mile logistics-using best practices, case studies and making the link with green and sustainable logistics. Association for European Transport and contributors (2009)

5. Jlassi, S., Tamayo, S., Gaudron, A.: Simulation Applied to Urban Logistics: A State of the Art. In: 10th International Conference on City Logistics, Phuket (2017)

6. Lagorio, A., Pinto, R., Golini, R.: Research in urban logistics: a systematic literature review. International Journal of Physical Distribution \& Logistics Management (2016)

7. Nunamaker, J.F., Briggs, R.O., Derrick, D.C., Schwabe, G. The last research mile: Achieving both rigor and relevance in information systems research. Journal of Management Information Systems, vol. 32, no. 3, pp.10-47 (2015)

8. Miah, S.J., Genemo, H.: A design science research methodology for expert systems development. Australasian Journal of Information Systems, vol. 20 (2016)

9. Karakikes, I., Nathanail, E., Savrasovs, M.: Techniques for Smart Urban Logistics Solutions' Simulation: A Systematic Review. In: International Conference on Reliability and Statistics in Transportation and Communication, pp. 551-561. Springer, Cham (2018)

10. Dolati Neghabadi, P., Evrard Samuel, K., Espinouse, M. L.: Systematic literature review on city logistics: overview, classification and analysis. International Journal of Production Research, vol. 5, no. 3, pp. 865-887 (2019)

11. Kollamthodi, S., Hitchcock, G., Fiorello, D., DeStasio, C.: Development of a Web-Based Tool to Support the Development of City-Level Urban Transport Roadmaps to 2030, no. 16-5913 (2016)

12. Bozzo, R., Conca, A., Marangon, F.: Decision support system for city logistics: literature review, and guidelines for an ex-ante model. Transportation Research Procedia, vol. 3, pp. 518527 (2014)

13. Hunt, J.D., Stefan, K.J.: Tour-based microsimulation of urban commercial movements. Transportation Research Part B: Methodological, vol. 41, no. 9, pp. 981-1013 (2007)

14. Joubert, J.W., Fourie, P.J., Axhausen, K.W.: Large-scale agent-based combined traffic simulation of private cars and commercial vehicles. Transportation Research Record, vol. 2168, no. 1, pp. 24-32 (2010)

15. Soares, G., Kokkinogenis, Z., Macedo, J.L., Rossetti, R.J.: Agent-based traffic simulation using sumo and jade: an integrated platform for artificial transportation systems. In: Simulation of Urban Mobility User Conference, pp. 44-61, Springer, Berlin, Heidelberg (2013)

16. Schröder, S., Dabidian, P., Liedtke, G.: A conceptual proposal for an expert system to analyze smart policy options for urban CEP transports. In: 2015 Smart Cities Symposium Prague (SCSP), pp. 1-6. IEEE (2015) 
17. Silva, W.T.P.D., Souza, M.A.A.D.: Expert system for selecting and prioritizing projects for handling urban water supply crises. Urban Water Journal, vol. 15, no. 6, pp. 561-567 (2018)

18. Peffers, K., Tuunanen, T., Rothenberger, M.A., Chatterjee, S.: A design science research methodology for information systems research. Journal of Management Information Systems, vol. 24, no. 3, pp. 45-77 (2007)

19. Miah, S.J., Gammack, J.G., McKay, J.: A Metadesign theory for Tailorable decision support. Journal of the Association for Information Systems, vol. 20, no. 5, p. 4 (2019)

20. Arnott, D., Pervan, G.: Design science in decision support systems research: An assessment using the Hevner, March, Park, and Ram Guidelines. Journal of the Association for Information Systems, vol. 13, no. 11, p. 1 (2012)

21. Holsapple, C.W.: DSS architecture and types. In Handbook on Decision Support Systems vol. 1, pp. 163-189. Springer, Berlin, Heidelberg (2008)

22. Connect Fahrplanauskunft GmbH: Connect-OpenData-Pool. (2019)

23. Bundesministerium für Verkehr und digitale Infrastruktur: Mobilität in Deutschland (MiD) 2017 (2018)

24. Bundesministerium für Verkehr und digitale Infrastruktur: Deutsches Mobilitätspanel 2015/2016 (MOP), Dataset (2016)

25. Bienzeisler, L., Lelke, T., Wage, O., Thiel, F., Friedrich, B.: Development of an Agent-Based Transport Model for the City of Hanover Using Empirical Mobility Data and Data Fusion. Transportation Research Procedia, vol.47, pp. 99-106 (2020)

26. Auf der Landwehr, M., Trott, M., von Viebahn, C.: E-Grocery in Terms of Sustainability Simulating the Environmental Impact of Grocery Shopping for an Urban Area in Hanover. Simulation in Produktion und Logistik 2019, Matthias Putz \& Andreas Schlegel (eds.), Wissenschaftliche Scripten, Auerbach (2019)

27. Waterman, D. A.: A guide to expert systems: Reading. Mass. Addison-Wesley, UK (1986)

28. Shearer, C.: The CRISP-DM model: the new blueprint for data mining. Journal of data warehousing, vol. 5, no. 4, pp. 13-22 (2000)

29. Quinlan, J.R.: C4. 5: Programs for machine learning. Morgan Kaufmann, San Francisco (1993)

30. Wu, X., Kumar, V., Quinlan, J.R., Ghosh, J., Yang, Q., Motoda, H., McLachlan, G.J., Ng, A., Liu, B., Philip, S.Y., Zhou, Z.H.: Top 10 algorithms in data mining. Knowledge and information systems, vol. 14, no. 1, pp.1-37 (2008)

31. Witten, I. H., Frank, E., Hall, M. A.: Data Mining, ser. Practical, Machine Learning Tools and Techniques. Morgan Kaufmann, San Francisco (2011)

32. Kapoor, P., Rani, R.: Efficient decision tree algorithm using J48 and reduced error pruning. International Journal of Engineering Research and General Science, vol. 3, no. 3, pp. 1613$1621(2015)$

33. Ninnemann, J., Hölter, A.K., Beecken, W., Thyssen, R., Tesch, T.: Last-Mile-Logistic Hamburg-Innerstädtische Zustelllogistik. Studie im Auftrag der Behörde für Wirtschaft, Verkehr und Innovation der Freien und Hansestadt Hamburg. Hamburg: HSBA Hamburg School of Business Administration. (2017)

34. Iso, I.S.O.: Iec25010: 2011 systems and software engineering-systems and software quality requirements and evaluation (square)-system and software quality models. International Organization for Standardization, vol. 34, p. 2910 (2011)

35. Landeshauptstadt Hannover: Strukturdaten der Stadtteile und Stadtbezirke. Statistikstelle der Landeshauptstadt Hannover (2018)

36. Landeshauptstadt Dresden: Stadtteilkatalog 2018. Kommunale Statistikstelle, Dresden (2018)

37. Stadt Wolfsburg: Statistisches Jahrbuch 2018, Wolfsburg (2018) 